\title{
Effects of transient creep strain on post-tensioned concrete slabs in fire
}

\section{Ya Wei}

Former PhD Student, Department of Civil Engineering, The University of Hong Kong, Hong Kong, China

Francis T. K. Au

Professor, Department of Civil Engineering, The University of Hong Kong, Hong Kong, China (Corresponding author: francis.au@hku.hk)

\author{
Jing Li \\ Associate Professor, Department of Civil Engineering, \\ South China University of Technology, Guangzhou, China \\ Neil C. M. Tsang \\ Senior Lecturer, Department of Civil Engineering, Architecture \\ and Building, Coventry University, Coventry, UK
}

The effects of transient creep strain of concrete on post-tensioned concrete slabs in fire were investigated by means of numerical modelling. Employing the commercial package Abaqus, three-dimensional non-linear finite-element (FE) models were established. The thermal creep strain of prestressing steel tendons was explicitly incorporated into the FE models. Three concrete constitutive models were considered - a basic model without considering transient creep strain, a transient model explicitly considering transient creep strain and the Eurocode 2 (EC2) model, implicitly considering transient creep strain taken from BS EN 1992-1-2. Through comparing the numerical results with those obtained from available tests in the literature, excellent agreement was achieved. Based on this, the basic model was verified at ambient temperature and both the EC2 model and the transient model were also verified in test fire scenarios. A main conclusion from this study is that transient creep strain should be considered either explicitly or implicitly in numerical modelling for its positive contribution to the fire resistance of slabs.

\begin{tabular}{|c|c|}
\hline \multicolumn{2}{|c|}{ Notation } \\
\hline$A, B, C$ & parameters in Nielsen's model \\
\hline$f_{\mathrm{c}}$ & $\begin{array}{l}\text { compressive strength of concrete at ambient } \\
\text { temperature }\end{array}$ \\
\hline$f_{\mathrm{c} T}$ & $\begin{array}{l}\text { compressive strength of concrete at elevated } \\
\text { temperature } T\end{array}$ \\
\hline$H$ & $\begin{array}{l}\text { Heaviside function for the } i \text { th eigenvalue of stress } \\
\text { tensor }\end{array}$ \\
\hline $\boldsymbol{I}$ & fourth-order identity tensor \\
\hline$k_{\mathrm{c}}$ & $\begin{array}{l}\text { reduction factor of strength of concrete at elevated } \\
\text { temperatures in BS EN 1992-1-2 (BSI, 2004) }\end{array}$ \\
\hline$n_{i}$ & $i$ th normalised eigenvector of stress tensor \\
\hline $\boldsymbol{P}^{+}, \boldsymbol{P}^{-}$ & fourth-order projection tensors \\
\hline$p_{i j}$ & second-order tensor \\
\hline$s_{i j}$ & deviatoric stress tensor \\
\hline$T$ & temperature in ${ }^{\circ} \mathrm{C}$ \\
\hline $\bar{T}$ & temperature in Kelvin \\
\hline$T_{\max }$ & maximum temperature \\
\hline$y$ & function of temperature in Nielsen's model \\
\hline$\beta_{\mathrm{cr}}$ & parameter of thermal creep model proposed by \\
\hline & Harmathy for concrete \\
\hline$\beta_{\text {tr }}$ & coefficient of uniaxial transient strain \\
\hline$\Delta T$ & temperature increment \\
\hline$\Delta t$ & time increment \\
\hline$\Delta \varepsilon$ & strain increment \\
\hline$\Delta \sigma$ & stress increment \\
\hline$\delta_{i j}$ & Kronecker delta \\
\hline
\end{tabular}

$\begin{array}{ll}\varepsilon & \text { uniaxial strain } \\ \varepsilon_{\mathrm{cr}} & \text { thermal creep strain of concrete } \\ \varepsilon_{\mathrm{el}} & \text { elastic strain of concrete } \\ \varepsilon_{\mathrm{o} T} & \text { peak strain corresponding to } f_{\mathrm{c} T} \\ \varepsilon_{\mathrm{pl}} & \text { plastic strain of concrete } \\ \varepsilon_{\mathrm{th}} & \text { thermal expansion strain of concrete } \\ \varepsilon_{\mathrm{tot}} & \text { total strain of concrete } \\ \varepsilon_{\mathrm{tr}} & \text { transient strain of concrete } \\ \theta & \text { dimensionless variant depending on temperature in } \\ & \text { Nielsen's model } \\ \theta^{*} & \text { dimensionless constant at temperature of } 470^{\circ} \mathrm{C} \text { in } \\ & \text { Nielsen's model } \\ v & \text { Poisson's ratio of concrete } \\ \sigma & \text { uniaxial stress } \\ \sigma & \text { stress tensor } \\ \sigma^{+} & \text {positive component of stress tensor } \\ \sigma^{-} & \text {negative component of stress tensor } \\ \bar{\sigma} & \text { equivalent stress } \\ \Phi & \text { fourth-order function of temperature }\end{array}$

\section{Introduction}

Post-tensioned (PT) concrete slabs have been widely adopted in commercial and residential buildings due to their prominent merits of reducing span-to-depth ratios and enhancing the load-carrying capacities of slabs. These merits are achieved by a suitable layout of prestressing steel tendons in a slab, in 
parabolic, draped or straight profiles. The forces of the tendons can be transferred to the slab through the profiles, putting its cross-section in compression. When PT concrete slabs are exposed to fire, transient creep strain will be induced by both the transient heating and compressive stresses. Preloaded concrete under first-time heating experiences considerable contraction compared with free thermal expansion; the difference is attributed to load-induced thermal strain comprising transitional thermal creep, drying creep, basic creep and changes in elastic strain with temperature (Khoury et al., 1985a). Transient creep strain mainly refers to the combined effects of transitional thermal creep and drying creep. Even though transient creep is known to have adverse effects on the fire resistance of columns under compression (Gernay, 2012; Huang and Burgess, 2012a, 2012b; Sadaoui and Khennane, 2009), its effect on the fire resistance of PT concrete slabs in fire has not been elucidated so far. Thorough exploration of the effects of transient creep is therefore desirable for a better understanding of the structural fire performance of PT concrete slabs.

Various tests of PT concrete slabs in fire have been conducted by Gao et al. (2004), Yuan et al. (2006), Bailey and Ellobody (2009) and Zheng et al. (2010), which have resulted in better understanding of the structural fire performance of slabs and the implications for fire resistance design. However, tests are expensive and limited in their capacity for exploring the specific performance mechanisms of slabs in fire. As a cost-effective alternative approach, numerical modelling has been increasingly adopted in evaluating the structural fire performance of slabs (Caldas et al., 2013; Ellobody and Bailey, 2008b, 2009; Lim et al., 2004). In numerical modelling, material properties at elevated temperatures, especially the constitutive relationship and compressive strength of concrete, are essential inputs for evaluating the performance of slabs in fire. Thorough literature reviews of the constitutive relationships and compressive strength of concrete at elevated temperatures have been presented by Phan and Carino (1998), Hertz (2005), Li and Purkiss (2005) and Youssef and Moftah (2007), and these provide a useful database of concrete for numerical modelling of structures or structural elements in fire. Although the transient creep strain of concrete is often implicitly taken into account in numerical modelling based on BS EN 1992-1-2 (BSI, 2004) and gives acceptable results, it is unclear how transient creep strain affects the performance of slabs subjected to fire and whether the simplified model is really reliable in such applications.

Generally, the stress-strain relationship of concrete at elevated temperature is obtained from tests at steady state. In other words, stress-strain curves are often obtained under constant temperature, similar to tests conducted at ambient temperature during which only time-independent mechanical strains comprising elastic and plastic strains are mainly included (Anderberg and Thelandersson, 1976). There are two ways of invoking transient creep strain in tests to the stress-strain curve to make it more robust for transient heating analysis. One way is to modify the stress-strain relationship to incorporate transient creep strain implicitly ( $\mathrm{Li}$ and Purkiss, 2005) as, for example, in the stress-strain constitutive model of concrete in BS EN 1992-1-2 (BSI, 2004). The other way is to add transient creep strain to the stress-strain curve explicitly, during which an iterative calculation is needed based on the current compressive stress and elevated temperature (Gernay and Franssen, 2012). Comparing the two ways of considering transient creep strain, the former is relatively simple and approximate in nature, while the latter can be more accurate (Gernay, 2012).

In this study, the effects of transient creep strain of concrete on PT concrete slabs with unbonded tendons were investigated by numerical modelling. Three-dimensional (3D) non-linear finiteelement (FE) models of PT concrete slabs were established by employing the commercial package Abaqus. To highlight the effects, three concrete constitutive models were adopted - one without transient creep strain and the other two with either explicit or implicit consideration of transient creep strain.

\section{Stress-strain relationship of concrete at elevated temperatures}

The total strain of concrete under load at elevated temperatures can be decomposed into the components of elastic strain $\varepsilon_{\mathrm{el}}$, plastic strain $\varepsilon_{\mathrm{pl}}$, transient strain $\varepsilon_{\mathrm{tr}}$ thermal expansion strain $\varepsilon_{\mathrm{th}}$ and basic creep strain $\varepsilon_{\mathrm{cr}}$, although the last one is often neglected in view of its small magnitude. In this study, the basic creep strain is explicitly considered as part of the transient creep strain. The total strain is mathematically expressed by

1. $\varepsilon_{\mathrm{tot}}=\varepsilon_{\mathrm{el}}+\varepsilon_{\mathrm{pl}}+\varepsilon_{\mathrm{th}}+\varepsilon_{\mathrm{tr}}+\varepsilon_{\mathrm{cr}}$

where the subscripts th, tr and cr, which respectively denote quantities of the thermal expansion strain, transient strain and basic creep strain, are also applied to other notation in this paper.

\section{Instantaneous stress-strain relationships at elevated} temperatures

The model proposed by Schneider (1986) for normal-strength concrete is used to describe the stress-strain relationship of concrete exposed to elevated temperatures, as shown by

2. $\quad \sigma=\frac{3 \varepsilon f_{\mathrm{c} T}}{\varepsilon_{\mathrm{o} T}\left[2+\left(\varepsilon / \varepsilon_{\mathrm{o} T}\right)^{3}\right]}$

where $\sigma$ is the stress and $\varepsilon$ is the corresponding instantaneous strain, $f_{\mathrm{c} T}$ is the compressive strength of concrete at temperature $T\left({ }^{\circ} \mathrm{C}\right)$ and $\varepsilon_{\mathrm{o} T}$ is the peak strain corresponding to $f_{\mathrm{c} T}$

The concrete strength $f_{\mathrm{c} T}$ at elevated temperature is obtained using the reduction factor $k_{\mathrm{c}}$ based on the concrete strength $f_{\mathrm{c}}$ 
at ambient temperature

3. $f_{\mathrm{c} T}=k_{\mathrm{c}} f_{\mathrm{c}}$

where $k_{\mathrm{c}}$ is taken from tabulated data for concrete with siliceous aggregate presented in BS EN 1992-1-2 (BSI, 2004).

The peak strain of concrete at elevated temperature is described by the model proposed by Terro (1998), assuming zero initial stress, as

4.

$$
\begin{aligned}
\varepsilon_{\mathrm{o} T}= & 2.05 \times 10^{-3}+3.08 \times 10^{-6} T+6.17 \times 10^{-9} T^{2} \\
& +6.58 \times 10^{-12} T^{3}
\end{aligned}
$$

The model obtained based on the above-mentioned constitutive model, concrete strength and peak strain at elevated temperature is hereafter called the basic model. The uniaxial stress-strain relationships of the basic model are obtained at various elevated temperatures. Comparison with the test data reported by Youssef and Moftah (2007) and Gawin et al. (2004) under various elevated temperatures (Figure 1) shows good agreement, indicating that the basic model performs well in accounting for the instantaneous stress-strain relationships at elevated temperatures.

For a uniaxial tension model, the tensile strength is taken to be $0 \cdot 1$ times the concrete compressive strength at various temperatures. The tensile stress-strain response is assumed to be linear before reaching the peak tensile strength, after which cracks propagate. Crack energy is used to account for the post-peak cracking behaviour of concrete (Wei and $\mathrm{Au}, 2014$ ).

\section{Transient strain}

Transient strain is difficult to measure directly. Generally, the strain is separated from the total strain measured from the concrete specimen under constant load subjected to transient heating. Models accounting for transient strain under uniaxial compression have been proposed by many researchers Anderberg and Thelandersson's model (Anderberg and Thelandersson, 1976), Diederichs's model introduced by Li and Purkiss (2005) and Youssef and Moftah (2007), Schneider's model (Schneider and Schneider, 2009), Terro's model (Terro, 1998), Nielsen's model described by Pearce et al. (2004) and Gernay and Franssen's model (Gernay and Franssen, 2012). Nielsen's model may be much more applicable for various kinds of concrete because it has three parameters to be identified based on test data. Gernay and Franssen's model may be much more generic as it was derived from the generic constitutive model for concrete at elevated temperatures taken from BS EN 1992-1-2 (BSI, 2004). Therefore, these two models were adopted in this study to consider the transient strain of concrete.

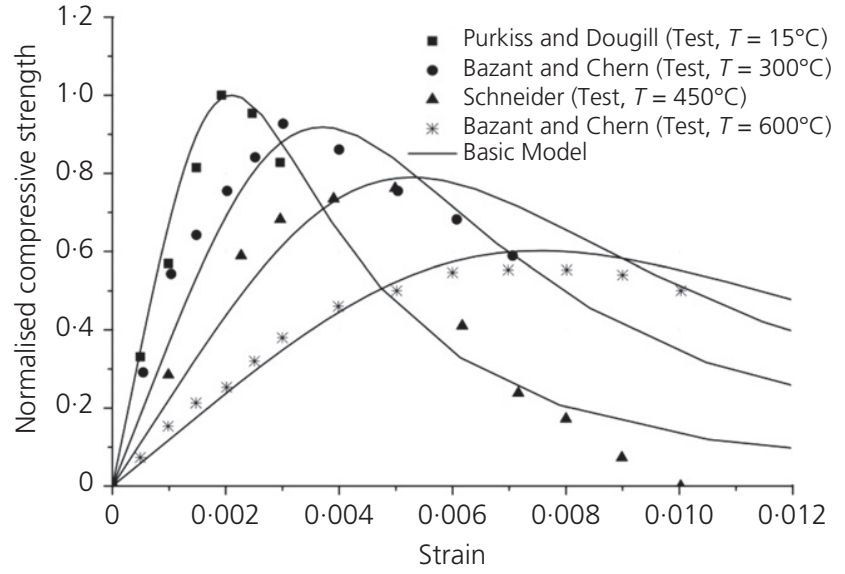

(a)

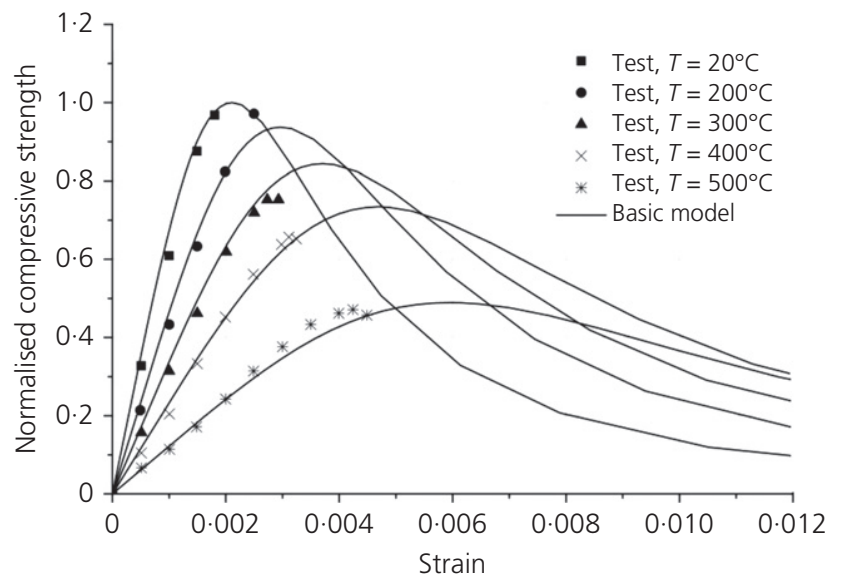

(b)

Figure 1. Stress-strain relationships of concrete at elevated temperatures predicted by basic model and obtained from tests:

(a) test results reported by Youssef and Moftah (2007); (b) tests results of Gawin et al. (2004)

Nielsen's model (Pearce et al., 2004)

As reported by Pearce et al. (2004), Nielsen presented a biparabolic expression to describe transient strain, given by

5. $\varepsilon_{\mathrm{tr}}=\frac{\sigma}{f_{\mathrm{c}}} y$

$$
y=\left\{\begin{array}{ccc}
A \theta^{2}+B \theta & \text { for } & 0 \leq \theta \leq \theta^{*}=4 \cdot 5 \\
C\left(\theta-\theta^{*}\right)^{2}+A\left(2 \theta-\theta^{*}\right)+B \theta & \text { for } & \theta>\theta^{*}
\end{array}\right.
$$

where $y$ is a function of temperature, $\theta$ is a dimensionless variant depending on temperature as $\theta=(T-20 / 100), \theta^{*}$ is a dimensionless constant as the transition at a temperature of $470^{\circ} \mathrm{C}$ and $A$, $B$ and $C$ are parameters that can be identified through testing. By fitting the test data from Khoury et al. (1985b) and Schneider (1986), as reported by Pearce et al. (2004), the 
parameters were identified as $A=0.0004, B=0.001$ and $C=0.007$ providing the lower bound and $A=0.0006, B=0.0015$ and $C=0.01$ providing the upper bound. The average of each of the parameters based on the lower bound and the upper bound (e.g. $A=0 \cdot 0005$ ) was adopted by Ožbolt et al. (2014) for transient analysis of concrete structures exposed to fire.

\section{Gernay and Franssen's model (Gernay and Franssen, 2012)}

In consideration of the dependence of transient strain on concrete, a generic transient model was proposed by Gernay and Franssen based on the generic constitutive model for concrete at elevated temperatures taken from BS EN 1992-1-2 (BSI, 2004) and experimental instantaneous stress-strain relationships. The transient strain was separated from the generic constitutive model, which could be used for explicit transient analysis for preloaded concrete exposed to fire. The proposed model for the transient strain is given by

6. $\varepsilon_{\mathrm{tr}}=\frac{\sigma}{f_{\mathrm{c}}} \Phi(T)$

$$
\Phi(T)=\left[\begin{array}{c}
1.5186 \times 10^{-4}+4.9405 \times 10^{-6} T+6.3213 \times 10^{-6} T^{2} \\
-4.7274 \times 10^{-11} T^{3}+2.1594 \times 10^{-13} T^{4}
\end{array}\right]
$$

where $\Phi(T)$ is a fourth-order function of temperature, obtained by the current authors by fitting the data presented by Gernay and Franssen (2012).

Moreover, a general formula of the transient strain increment $\Delta \varepsilon_{i j}^{\mathrm{tr}}$ under multi-axial stress state $\sigma_{i j}$ over a temperature increment $\Delta T$ was proposed by Thelandersson (1987). The formula was then adapted by Pearce et al. (2004) with consideration of the negative component of the stress tensor, making use of Poisson's ratio of concrete $v$ to relate the axial and lateral stress induced strains. The adapted formula has been widely adopted (e.g. De Sa and Benboudjema, 2011; Ožbolt et al., 2014) and is expressed as

7. $\Delta \varepsilon_{i j}^{\mathrm{tr}}\left(T, \sigma_{i j}\right)=\frac{\beta_{\mathrm{tr}}}{f_{\mathrm{c}}}\left[(1+v) \sigma_{i j}^{-}-v \sigma_{k k}^{-} \delta_{i j}\right] \Delta T\left(T_{\max }\right)$

$$
\Delta T\left(T_{\max }\right)=\Delta T \quad \text { for } \quad T \geq T_{\max }
$$

$$
\Delta T\left(T_{\max }\right)=0 \quad \text { for } \quad T<T_{\max }
$$

where the superscript ' - ' indicates the compressive part of the stress tensor, $T_{\max }$ is the maximum temperature so far reached and is introduced to recognise the irreversible nature of transient strain, $\beta_{\text {tr }}$ is the coefficient of uniaxial transient strain, $T$ is the temperature of concrete in ${ }^{\circ} \mathrm{C}$ and $f_{\mathrm{c}}$ is the compressive strength of concrete at ambient temperature.

The transient strain of concrete is assumed to occur only under compression when it is exposed to first-time transient heating. To characterise the transient strain of concrete due to compressive stress, the Cauchy stress tensor $\sigma$ is decomposed into a positive component $\sigma^{+}$and a negative component $\sigma^{-}$making use of the spectral decomposition technique (Cicekli et al., 2007; Wu et al., 2006). The positive component is given by

8. $\sigma^{+}=P^{+}: \sigma$

and the negative component is given by

9. $\sigma^{-}=\sigma-\sigma^{+}=P^{-}: \sigma$

where the fourth-order projection tensors $\boldsymbol{P}^{+}$and $\boldsymbol{P}^{-}$are defined as

10. $\boldsymbol{P}^{+}=\sum_{i} H\left(\sigma_{i}\right)\left(p_{i i} \otimes p_{i i}\right)$

11. $\boldsymbol{P}^{-}=\boldsymbol{I}-\boldsymbol{P}^{+}$

in which $I$ is the fourth-order identity tensor, $H\left(\sigma_{i}\right)$ is the Heaviside function of the $i$ th eigenvalue $\sigma_{i}$ of $\sigma, \otimes$ denotes the tensor product, and the second-order symmetric tensor $p_{i i}$ is defined by

12. $p_{i j}=p_{j i}=\frac{1}{2}\left(n_{i} \otimes n_{j}+n_{j} \otimes n_{i}\right)$

with $n_{i}$ being the $i$ th normalised eigenvector in respect of $\sigma_{i}$.

\section{Basic creep strain}

Basic creep is used to describe the strain of thermally stabilised concrete when loaded at constant temperature (Law and Gillie, 2008), which is usually neglected in short-term heating analysis but may be included in calculations for long-term heating and loading scenarios (Pearce et al., 2004). Generally, basic creep strain is obtained based on the measured deformation of concrete under constant temperature and sustained constant loading. Various models have been proposed to describe creep strain; in this study, the model proposed by Harmathy based on test data obtained by Cruz (1968) was adopted, namely

13. $\varepsilon_{\mathrm{cr}}=\beta_{\mathrm{cr}} \frac{\sigma}{f_{\mathrm{c} T}} \sqrt{t} \mathrm{e}^{d(\bar{T}-293)}$

where $\beta_{\mathrm{cr}}=6.28 \times 10^{-6} \mathrm{~s}^{-1 / 2}, d=2.658 \times 10^{-3} \mathrm{~K}^{-1}, t$ is time (in seconds) and $\bar{T}$ is the temperature of concrete in Kelvin. 
As reported by Bratina et al. $(2005,2007)$, the model was verified by excellent agreement with test data under various elevated temperatures.

The creep model was incorporated into the 3D FE models based on the assumption that creep deformation is dependent on the deviatoric stress component of the negative part of the stress tensor at an integration point. The creep increment $\Delta \varepsilon_{i j}^{\mathrm{cr}}$ under a multi-axial stress state is given as

14. $\Delta \varepsilon_{i j}^{\mathrm{cr}}=\frac{3 \Delta \varepsilon_{\mathrm{cr}}}{2 \bar{\sigma}_{n}^{-}} s_{i j}^{n}$

where $\bar{\sigma}_{n}^{-}$is the equivalent stress of the negative component of the stress tensor at time increment $n, s_{i j}^{n}$ is the deviatoric stress component of the negative part of the stress tensor at time increment $n$ and $\Delta \varepsilon_{\mathrm{cr}}$ is the increment of creep strain under the equivalent axial stress.

\section{Numerical modelling of post-tensioned concrete slabs in fire}

Numerical modelling was conducted based on the fire tests of PT concrete slabs conducted by Bailey and Ellobody (2009). The parameters taken into account in the tests included aggregate type and longitudinal restraint, which are summarised in Table 1. Non-linear FE models were established according to the geometrical dimensions of specimens and test conditions.

\section{Finite-element model}

The FE model was established employing the commercial package Abaqus, using 3D solid elements for the concrete and tendons, and 3D truss elements for the steel bars. Due to symmetry, only a quarter of the slab was modelled, as shown in Figure 2. Since each prestressing tendon was unbonded to the surrounding concrete, frictionless contact between them was incorporated in the model. Bursting reinforcement was embedded in the slab, assuming no slip between the steel bars and surrounding concrete.

\begin{tabular}{lllcc}
\hline $\begin{array}{l}\text { Test } \\
\text { type }\end{array}$ & $\begin{array}{l}\text { Longitudinal } \\
\text { thermal } \\
\text { expansion }\end{array}$ & $\begin{array}{c}\text { Concrete cube } \\
\text { strength: } \\
\text { MPa }\end{array}$ & $\begin{array}{c}\text { Moisture } \\
\text { content: } \\
\%\end{array}$ \\
\hline T1 & Limestone & Free & $44 \cdot 4$ & - \\
T2 & Thames gravel & Free & $48 \cdot 2$ & - \\
T3 & Limestone & Free & $48 \cdot 0$ & $2 \cdot 54$ \\
T4 & Limestone & Restrained & \\
T5 & Thames gravel & Free & $41 \cdot 0$ & $2 \cdot 15$ \\
T6 & Thames gravel & Restrained & \\
& & & $39 \cdot 0$ & $2 \cdot 34$ \\
\end{tabular}

${ }^{a}$ Overall slab was allowed to initially expand $2 \mathrm{~mm}$ before it was restrained

Table 1. Details of tests conducted by Bailey and Ellobody (2009)

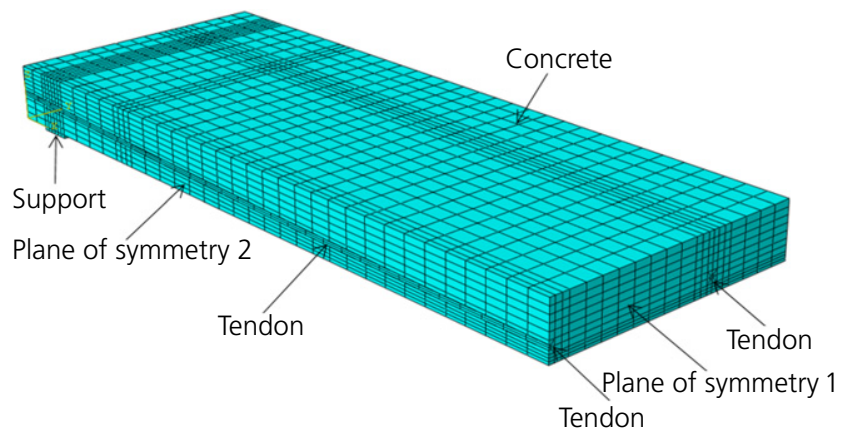

Figure 2. Finite-element model for a quarter of the PT concrete slab

The prestressing steel strands had a measured elastic modulus of $227 \mathrm{GPa}$, yield strength of $1710 \mathrm{MPa}$ and ultimate strength of $1867 \mathrm{MPa}$ at ambient temperature (Ellobody and Bailey, 2008a). At elevated temperatures, the mechanical properties were reduced according to the reduction factors prescribed in BS EN 1992-1-2 (BSI, 2004). Stress-strain responses of the prestressing steel strands accounting for elastic-plastic linear hardening with the explicit consideration of thermal creep were used (Wei and Au, 2014).

\section{Results and validation}

The concrete constitutive models (the basic model, Eurocode 2 (EC2) model and the transient model) were incorporated into the FE models, where Nielsen's model and Gernay and Franssen's model were used to account for the transient strain. The results obtained from numerical modelling based on the three constitutive models were compared with those obtained from tests at ambient temperature and in fire scenarios.

\section{Responses of slabs at ambient temperature}

Tests T1 and T2 were conducted by Ellobody and Bailey (2008a) at ambient temperature, based on which numerical modelling was conducted using the basic model for concrete. Figure 3 shows the numerical modelling and test results, which show reasonable agreement in predicting the initial central deflection and variation of tendon strain. For test T1, Figure 3(a) shows that the predicted load-deflection relationship agrees well with that of the test within the first $60 \mathrm{~mm}$. Beyond this, the predicted load capacity increases with the central deflection, although the load capacity obtained from the test remains nearly constant, possibly because of increased difficulty of convergence in modelling the post-peak phase of the concrete constitutive relationship associated with plastic hinge formation in the test. The maximum load capacity predicted by numerical modelling was $179 \cdot 2 \mathrm{kN}$ at a central deflection of $96.6 \mathrm{~mm}$ when the tendon yielded, while that of the test was $156.7 \mathrm{kN}$ at a central deflection of $81.9 \mathrm{~mm}$ when the concrete crushed and the tendon yielded. For test T2, Figure 3(b) shows that the predicted load-deflection relationship also agrees well with the 


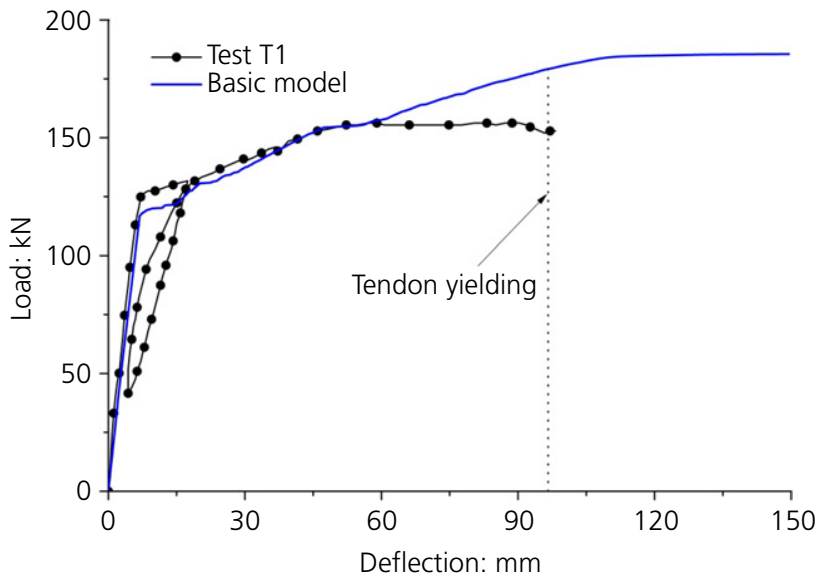

(a)

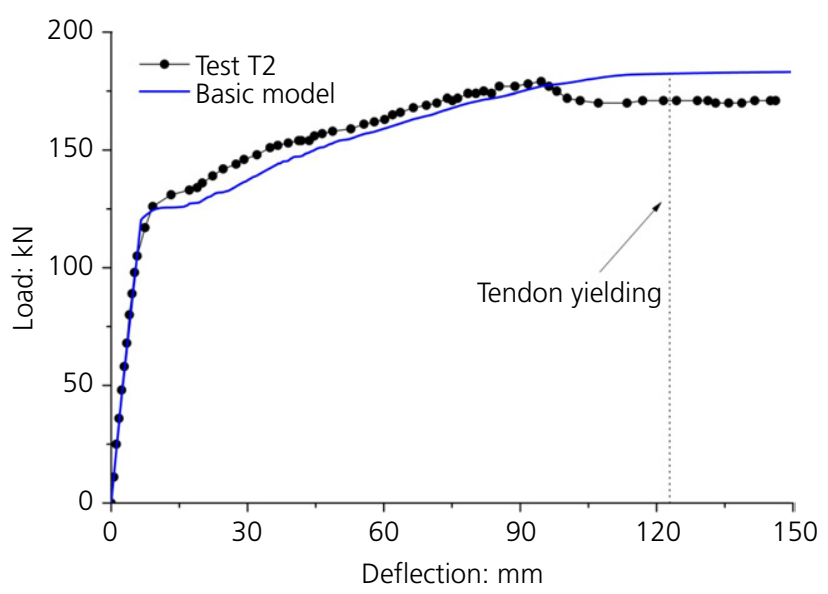

(b)

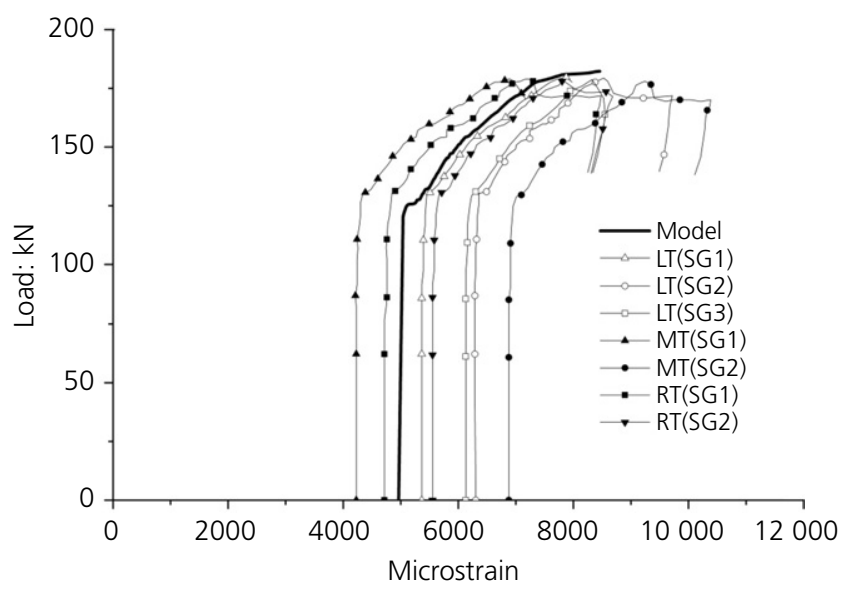

(c)

Figure 3. Comparison of results from numerical modelling with those from tests at ambient temperature: (a) load-deflection curve of $\mathrm{T} 1$; (b) load-deflection curve of $\mathrm{T} 2$; (c) load-strain curve of prestressing tendon of $\mathrm{T} 2$

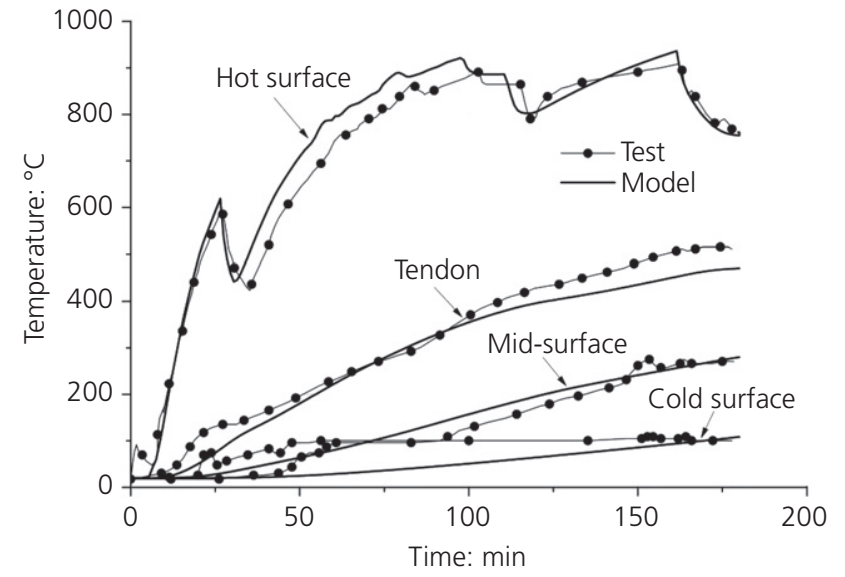

(a)

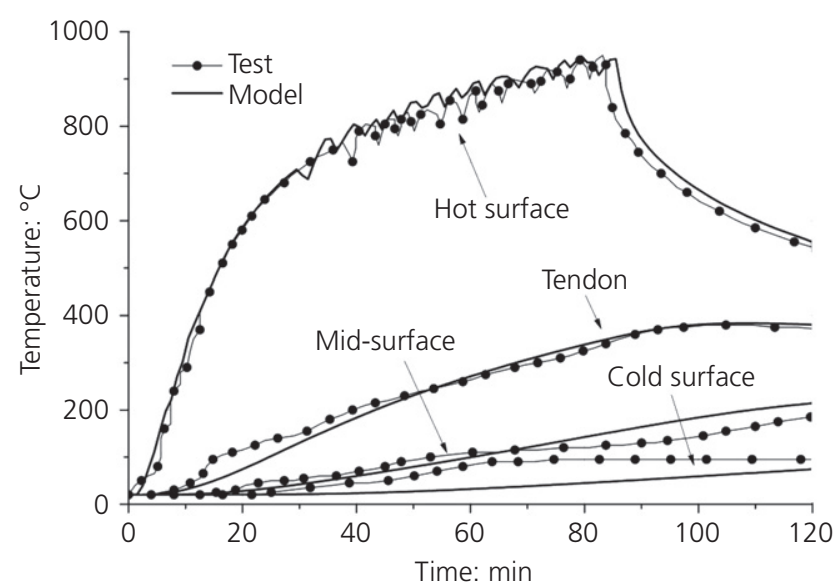

(b)

Figure 4. Comparison of predicted temperature fields with those obtained from (a) test T3 and (b) test T4

test results. The predicted maximum load capacity was $182.3 \mathrm{kN}$ at a central deflection of $122.9 \mathrm{~mm}$, which is slightly higher than the $178.2 \mathrm{kN}$ at a deflection of $93.5 \mathrm{~mm}$ obtained from the test. Figure 3(c) shows that the predicted variation of tendon strain with load agrees well with those of individual tendons in the test, in which LT, MT and RT indicate the left, middle and right tendons, respectively, and SG1, SG2 and SG3 denote their corresponding strain gauges. The obvious increase of tendon strain appears when the load reached approximately $125.5 \mathrm{kN}$ in the numerical modelling, which is slightly lower than the $130.9 \mathrm{kN}$ measured in the test. It is therefore verified that the FE model incorporating the basic model for concrete performs well at ambient temperature.

\section{Temperature fields of slabs in test fire scenarios}

As input data in the numerical modelling, the thermal properties of the concrete and prestressing steel, including thermal conductivity and specific heat, were taken from BS EN 1992-12 (BSI, 2004) and BS EN 1993-1-2 (BSI, 2005). The moisture 
content of the concrete was taken into account by adjusting the specific heat at a temperature of $115^{\circ} \mathrm{C}$. According to $\mathrm{BS}$ EN 1991-1-2 (BSI, 2002), a constant convection factor of $25 \mathrm{~W} / \mathrm{m}^{2} \mathrm{~K}$ and a constant emissivity of 0.8 were set for the fire-exposed surface, while $9 \mathrm{~W} / \mathrm{m}^{2} \mathrm{~K}$ was set for the surface not exposed to fire. The contact thermal conductivity between the prestressing steel tendon and the surrounding concrete was assumed to be $200 \mathrm{~W} / \mathrm{m}^{2} \mathrm{~K}$.

The temperature fields predicted by the numerical modelling were compared with those obtained from tests based on test fire scenarios of T3 and T4 (Bailey and Ellobody, 2009). The comparison is shown in Figure 4 in respect of the hot surface (the bottom surface of the slab exposed to fire), tendon (the tendon in the mid-span of slab), mid-surface (the middle height of slab) and cold surface (the top surface of the slab exposed to ambient temperature), which shows that excellent agreement was achieved for both T3 and T4. It was thus verified that the input thermal properties were sufficiently accurate,

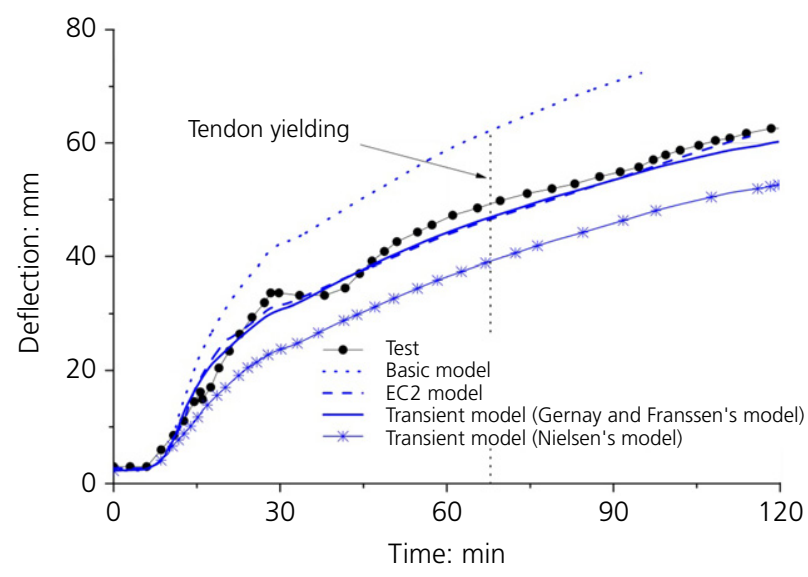

(a)

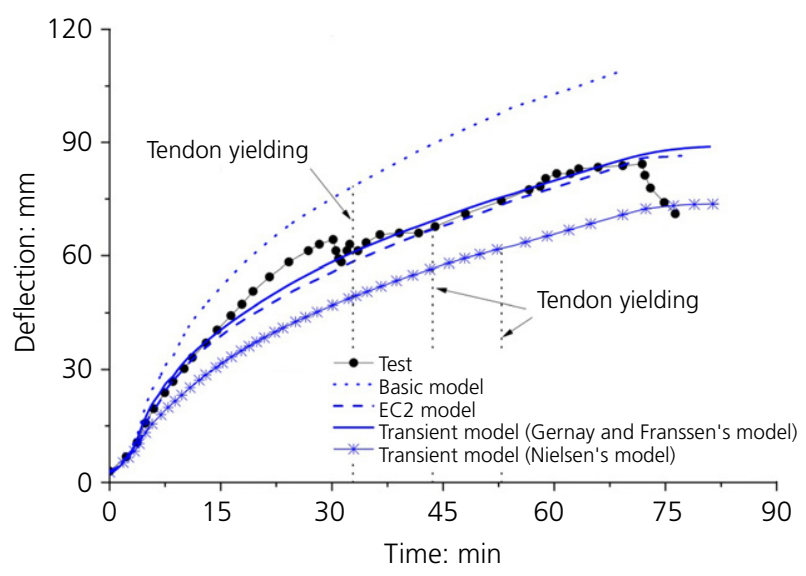

(c) although there was an obvious discrepancy for the cold surface, as shown in Figures 4(a) and 4(b). This is because moisture transportation from inside the concrete to the top of the slab affects the temperature of the cold surface, while the phenomenon of water transportation is difficult to simulate in numerical modelling. However, when the temperature is not too high, this discrepancy can be ignored.

\section{Responses of slabs in test fire scenarios}

Fire tests T3, T4, T5 and T6 were conducted by Bailey and Ellobody (2009) with the parameters shown in Table 1; the concrete used for both T3 and T4 contained limestone aggregate, while that used for tests $\mathrm{T} 5$ and $\mathrm{T} 6$ contained Thames gravel aggregate. Both T3 and T5 were free for longitudinal thermal expansion. Because of the clearance holes at the fixing bolts, both T4 and T6 were allowed to expand initially for $2 \mathrm{~mm}$ before they became fully restrained longitudinally by the supporting beams. In the numerical modelling, the thermal expansion coefficient of the concrete with limestone aggregate

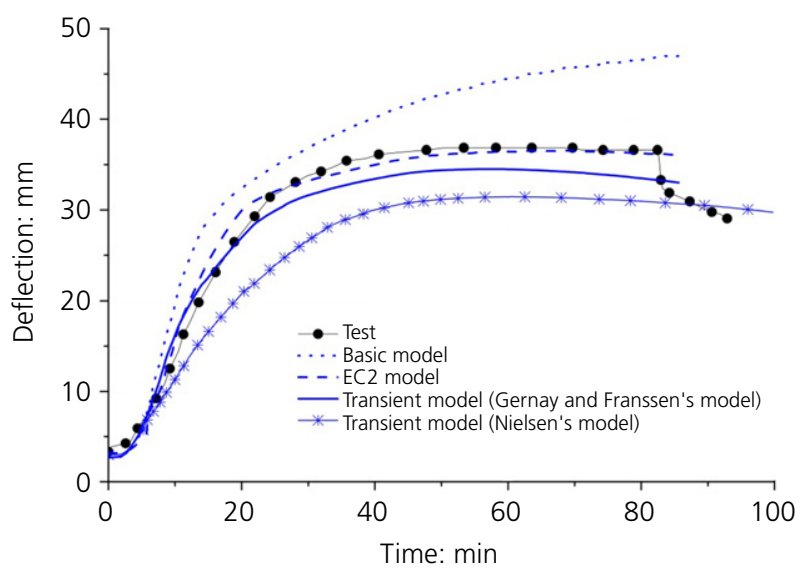

(b)

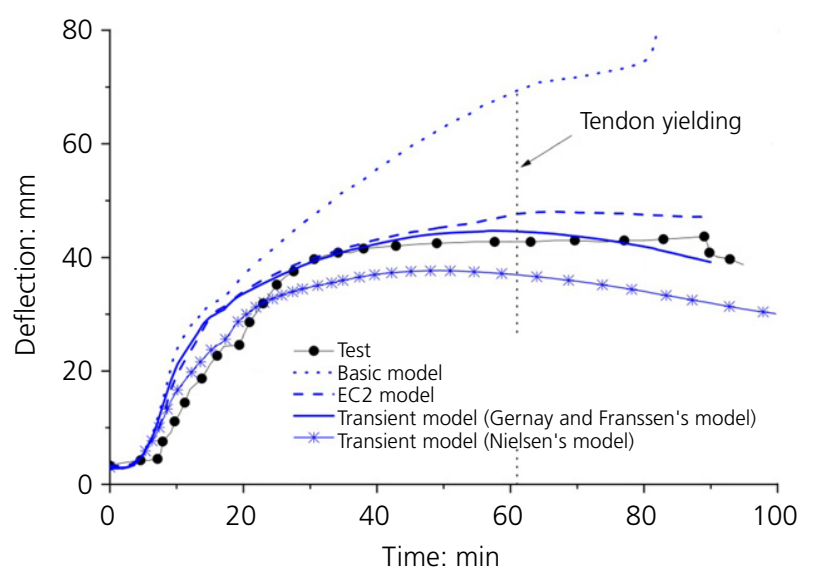

(d)

Figure 5. Comparison of predicted central deflections of slabs based on various concrete constitutive models with those obtained from (a) test T3, (b) test T4, (c) test T5 and (d) test T6 


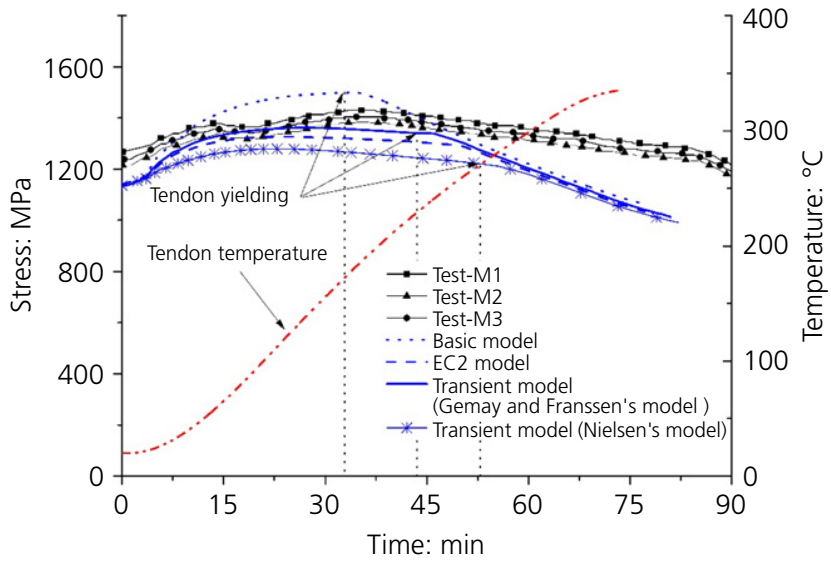

Figure 6. Comparison of predicted tendon stress based on various models with those obtained from test T5

was taken as $8 \cdot 1 \times 10^{-6}$ and that with Thames gravel aggregate was taken as $13.2 \times 10^{-6}$. Discrete rigid elements were adopted in the FE model to simulate the restraining beam, and the normal contact (in the longitudinal direction as shown in Figure 2) between the surfaces of the discrete rigid elements and that of the slab was used to account for the longitudinal restraint.

The central deflections of the slabs obtained from numerical modelling were compared with those obtained from tests, as shown in Figures 5(a)-5(d) for tests T3 to T6, respectively. The figures show that the predicted deflections by numerical modelling based on the EC2 model and the transient model with Gernay and Franssen's model for transient strain agree well with those obtained from tests. However, the predicted deflections based on the basic model are much higher than those of the tests. The deflections predicted based on the transient model with Nielsen's model for transient strain are much lower than those of the tests. While the transient model with Gernay and Franssen's model takes transient strain into account explicitly and the EC2 model accounts for transient creep strain implicitly, the basic model does not consider transient creep strain, thereby resulting in larger total strain of concrete at the slab soffit, larger bending curvature and, finally, much higher slab deflection. On the other hand, the transient model with Nielsen's model for transient strain overestimates the transient strain, thereby resulting in lower total strain of concrete at the slab soffit, a smaller bending curvature and much lower slab deflection. Interestingly, when tendon yielding occurred, the corresponding deflections all exceeded $60 \mathrm{~mm}$. Moreover, the larger the thermal expansion coefficient or the smaller the transient strain, the earlier tendon yielding occurs.

Figure 6 compares the predicted tendon stress from numerical modelling based on the three concrete constitutive models with those obtained from three wires of the middle tendon in test
T5. The predicted tendon stresses based on the transient model with Gernay and Franssen's model for transient strain and the EC2 model are much closer to the test data during the first $45 \mathrm{~min}$ of the fire test. Afterwards, the predicted stress gradually departs from the test data. Tendon yielding occurred at a temperature of about $225^{\circ} \mathrm{C}$, as predicted by the transient model. This suggests that the thermal creep of prestressing steel is possibly underestimated so that the tendon appears to yield early. Moreover, the tendon stress predicted by the basic model develops at a higher rate until tendon yielding and then drops as in the other models, with the predicted maximum stress being much higher than the test data. This is related to the larger deflection. The tendon stress predicted by the transient model with Nielsen's model for transient strain develops at a lower rate initially and then gradually decreases, with the predicted stress being much lower than the test data. The tendon is predicted to yield in about $50 \mathrm{~min}$.

\section{Conclusions}

A comparison of results obtained from numerical modelling with those from tests in respect of deflection and tendon stress shows that the basic model is sufficiently accurate at ambient temperature, but is too conservative in test fire scenarios by predicting much larger deflection and higher tendon stress. Both the EC2 model and the transient model yield accurate predictions in test fire scenarios. However, if the transient creep strain is overestimated, the slab deflection and the tendon stresses will be reduced, which means that transient creep strain has a positive effect on structural fire resistance. The findings thus indicate that transient creep strain should be taken into consideration, by either an implicit or explicit approach, for its positive contribution to the fire resistance of post-tensioned concrete slabs.

\section{Acknowledgement}

The work reported here was supported by the Research Grants Council (RGC) of Hong Kong Special Administrative Region, China (RGC project no. HKU 710012E).

\section{REFERENCES}

Anderberg Y and Thelandersson S (1976) Stress and Deformation Characteristics of Concrete, 2-Experimental Investigation and Material Behaviour Model. University of Lund, Lund, Sweden, Bulletin 54.

Bailey C and Ellobody E (2009) Fire tests on unbonded posttensioned one-way concrete slabs. Magazine of Concrete Research 61(1): 67-76, http://dx.doi.org/10.1680/macr.2008. 00005.

Bratina S, Cas B, Saje M and Planinc I (2005) Numerical modelling of behaviour of reinforced concrete columns in fire and comparison with Eurocode 2. International Journal of Solids and Structures 42(21-22): 5711-5733. 
Bratina S, Saje M and Planinc I (2007) The effects of different strain contributions on the response of $\mathrm{RC}$ beams in fire. Engineering Structures 29(3): 418-430.

BSI (2002) BS EN 1991-1-2: Eurocode 1: Actions on structures - part 1-2: general actions - actions on structures exposed to fire. BSI, London, UK.

BSI (2004) BS EN 1992-1-2: Eurocode 2: Design of concrete structures - part 1-2: general rules -structural fire design. BSI, London, UK.

BSI (2005) BS EN 1993-1-2: Eurocode 3: Design of steel structures - part 1-2: general rules - structural fire design. BSI, London, UK.

Caldas RB, Fakury RH, Sousa JBM and Pitanqueira RLS (2013) A numerical model for concrete slabs under fire conditions. Journal of Fire Protection Engineering 23(3): 177-189.

Cicekli U, Voyiadjis GZ and Al-Rub RKA (2007) A plasticity and anisotropic damage model for plain concrete. International Journal of Plasticity 23(10-11): 1874-1900.

Cruz CR (1968) Apparatus for measuring creep of concrete at high temperatures. Journal of the PCA Research and Development Laboratories 10(3): 36-42.

De Sa C and Benboudjema F (2011) Modeling of concrete nonlinear mechanical behavior at high temperatures with different damage-based approaches. Materials and Structures 44(8): 1411-1429.

Ellobody E and Bailey C (2008a) Behaviour of unbonded post-tensioned one-way concrete slabs. Advances in Structural Engineering 11(1): 107-120.

Ellobody E and Bailey C (2008b) Modelling of bonded post-tensioned concrete slabs in fire. Proceedings of the Institution of Civil Engineers - Structures and Buildings 161(6): 311-323, http://dx.doi.org/10.1680/stbu.2008. 161.6.311.

Ellobody E and Bailey C (2009) Modelling of unbonded posttensioned concrete slabs under fire conditions. Fire Safety Journal 44(2): 159-167.

Gao LT, Dong YL and Yuan AM (2004) Experimental investigation of the behaviors of continuous slabs of unbonded prestressed concrete with the end span under fire. Journal of Building Structures 25(2): 118-123 (in Chinese).

Gawin D, Pesavento F and Schrefler BA (2004) Modelling of deformations of high strength concrete at elevated temperatures. Materials and Structures 37(268): 218-236.

Gernay T (2012) Effect of transient creep strain model on the behavior of concrete columns subjected to heating and cooling. Fire Technology 48(2): 313-329.

Gernay T and Franssen JM (2012) A formulation of the Eurocode 2 concrete model at elevated temperature that includes an explicit term for transient creep. Fire Safety Journal 51(7): 1-9.

Hertz KD (2005) Concrete strength for fire safety design. Magazine of Concrete Research 57(8): 445-453, http://dx. doi.org/10.1680/macr.2005.57.8.445.
Huang SS and Burgess IW (2012a) Effect of transient strain on strength of concrete and CFT columns in fire - part 1 : elevated-temperature analysis on a Shanley-like column model. Engineering Structures 44(6): 379-388.

Huang SS and Burgess IW (2012b) Effect of transient strain on strength of concrete and CFT columns in fire - part 2: simplified and numerical modelling. Engineering Structures 44(6): 389-399.

Khoury GA, Grainger BN and Sullivan PJE (1985a) Transient thermal strain of concrete: literature review, conditions within specimen and behaviour of individual constituents. Magazine of Concrete Research 37(132): 131-144, http://dx.doi.org/10.1680/macr.1985.37.132.131.

Khoury GA, Grainger BN and Sullivan PJE (1985b) Strain of concrete during first heating to $600^{\circ} \mathrm{C}$ under load. Magazine of Concrete Research 37(133): 195-215, http://dx.doi.org/10.1680/macr.1985.37.133.195.

Law A and Gillie M (2008) Load induced thermal strain: implications for structural behaviour. Proceedings of the 5th International Conference on Structures in Fire, Singapore, pp. 448-496.

Li LY and Purkiss J (2005) Stress-strain constitutive equations of concrete material at elevated temperatures. Fire Safety Journal 40(7): 669-686.

Lim L, Buchanan A, Moss P and Feanssen JM (2004) Numerical modelling of two-way reinforced concrete slabs in fire. Engineering Structures 26(8): 1081-1091.

Ožbolt J, Bošnjak J, Periškic G and Sharma A (2014) 3D numerical analysis of reinforced concrete beams exposed to elevated temperature. Engineering Structures 58: 166-174.

Pearce CJ, Nielsen CV and Bicanic N (2004) Gradient enhanced thermo-mechanical damage model for concrete at high temperatures including transient thermal creep. International Journal for Numerical and Analytical Methods in Geomechanics 28(7-8): 715-735.

Phan LT and Carino NJ (1998) Review of mechanical properties of HSC at elevated temperature. Journal of Materials in Civil Engineering 10(1): 58-64.

Sadaoui A and Khennane A (2009) Effect of transient creep on the behaviour of reinforced concrete columns in fire. Engineering Structures 31(9): 2203-2208.

Schneider U (1986) Concrete at high temperatures - a general review. Fire Safety Journal 13(1): 55-68.

Schneider U and Schneider M (2009) An advanced transient concrete model for the determination of restraint in concrete structures subjected to fire. Journal of Advanced Concrete Technology 7(3): 403-413.

Terro MJ (1998) Numerical modeling of the behavior of concrete structures in fire. ACI Structural Journal 95(2): 183-193.

Thelandersson S (1987) Modelling of combined thermal and mechanical action in concrete. Journal of Engineering Mechanics 113(6): 893-906.

Wei Y and Au FTK (2014) Effects of thermal creep of prestressed steel on post-tensioned concrete slabs in and 
after fire. Materials Science and Engineering Technology 45(4): 292-305.

Wu JY, Li J and Faria R (2006) An energy release rate-based plastic-damage model for concrete. International Journal of Solids and Structures 43(3-4): 583-612.

Youssef MA and Moftah M (2007) General stress-strain relationship for concrete at elevated temperatures. Engineering Structures 29(10): 2618-2634.
Yuan AM, Dong YL, Dai H, Li YH and Gao LT (2006) Experimental investigation of unbonded prestressed concrete continuous slab subjected to fire. Journal of Building Structures 27(6): 60-66 (in Chinese).

Zheng WZ, Hou XM, Shi DS and Xu MX (2010)

Experimental study on concrete spalling in prestressed slabs subjected to fire. Fire Safety Journal 45(5): 283-297.

\section{How can you contribute?}

To discuss this paper, please submit up to 500 words to the editor at journals@ice.org.uk. Your contribution will be forwarded to the author(s) for a reply and, if considered appropriate by the editorial board, it will be published as a discussion in a future issue of the journal. 